\title{
Application of Multichannel Active Vibration Control in a Multistage Gear Transmission System
}

\author{
Feng Zhang $\mathbb{D}^{1},{ }^{1}$ Weihao Sun $\mathbb{D}^{1},{ }^{1}$ Chao Liu $\mathbb{D}^{2},{ }^{2}$ Hongchao Xiao, ${ }^{1}$ and Yong Zhang ${ }^{1}$ \\ ${ }^{1}$ College of Mechanical Engineering and Automation, Huaqiao University, Xiamen, Fujian 361021, China \\ ${ }^{2}$ State Key Laboratory of Ultra-Precision Machining Technology, Department of Industrial and Systems Engineering, \\ The Hong Kong Polytechnic University, Hong Kong, China \\ Correspondence should be addressed to Feng Zhang; zhangfeng@hqu.edu.cn
}

Received 12 March 2021; Revised 7 November 2021; Accepted 15 January 2022; Published 10 February 2022

Academic Editor: Xian-Bo Wang

Copyright (C) 2022 Feng Zhang et al. This is an open access article distributed under the Creative Commons Attribution License, which permits unrestricted use, distribution, and reproduction in any medium, provided the original work is properly cited.

Gears are the most important parts of rotating machinery and power transmission devices. When gears are engaged in meshing transmission, vibration will occur due to factors such as gear machining errors, meshing rigidity, and meshing impact. The traditional FxLMS algorithm, as a common active vibration algorithm, has been widely studied and applied in gear transmission system active vibration control in recent years. However, it is difficult to achieve good performance in convergence speed and convergence precision at the same time. This paper proposes a variable-step-size multichannel FxLMS algorithm based on the sampling function, which accelerates the convergence speed in the initial stage of iteration, improves the convergence accuracy in the steady-state adaptive stage, and makes the modified algorithm more robust. Simulations verify the effectiveness of the algorithm. An experimental platform for active vibration control of the secondary gear transmission system is built. A piezoelectric actuator is installed on an additional gear shaft to form an active structure and equipped with a signal acquisition system and a control system; the proposed variable-step-size multichannel FxLMS algorithm is experimentally verified. The experimental results show that the proposed multichannel variable-step-size FxLMS algorithm has more accurate convergence accuracy than the traditional FxLMS algorithm, and the convergence accuracy can be increased up to $123 \%$.

\section{Introduction}

As a general-purpose part, gear is an important transmission device in various mechanical equipment systems and plays a very key role in equipment in machinery, transportation, chemical, aviation, aerospace, shipbuilding, and other industries. In actual applications, the gears inevitably have manufacturing and installation errors, and the gear teeth will deform under the action of the load. These errors and deformations destroy the meshing relationship of the gear transmission and make the position of the gear melshing deviate from its theoretical position so that the instantaneous transmission ratio changes, causing the collision and impact between the teeth and forming the gear meshing. Internal excitation results in vibration and noise [1-4].

The vibration of the gear system will not only produce noise and lead to the instability of the transmission system, but also accelerate the fatigue damage of the transmission system and cause its failure and serious consequences [5]. For example, one of the main excitation sources of the helicopter body is the vibration from the transmission system [6]. Excessive vibration levels will cause discomfort to the crew, cause fatigue, affect work efficiency, and reduce the precision and reliability of precision instruments and weapon aiming systems, or even fail to work normally. Besides, vibration and noise will cause fatigue damage and damage to some components, which directly affects the flight reliability of the helicopter [7-9]. The problem of vibration and noise of a helicopter is more prominent than that of other aircraft. If part of the vibration and noise can be eliminated during the operation of the helicopter, it has important practical significance to ensure the flight safety of the helicopter and improve the ride comfort $[10,11]$. 
For the study of the vibration of the gear transmission system, in 1967, British scholar H. Optiz published an article on the dynamic performance of spur gear and the helical gear. According to the mechanism of gear vibration and noise, it is concluded that the vibration of gearbox and noise is a function of gear transmission error and precision, and some valuable analysis curves are given. Since the mid1970 s, the research objects of many scholars are mainly flexible rotors under high speed, such as rotors on highspeed high-precision machine tools and centrifugal units, which are usually under supercritical speed. How to restrain the rotor vibration, prevent the overall instability, and ensure the safe operation of the rotor has become a key problem. In the aspect of active control actuator, electromagnetic bearing and electromagnetic damper are studied more. As early as 1980, Haberman and Brunet [12] studied the stiffness characteristics of electromagnetic bearing and proposed the "bathtub" shaped complex stiffness curve. Since then, most researchers have analyzed the supporting characteristics of the electromagnetic bearing system based on this. Zhang and Zhang [13] reviewed in detail the research progress of unbalanced control technology of electromagnetic bearing. Maslen et al. [14] made a comprehensive review and summary of the existing unbalanced vibration control methods and the latest research results in the field of electromagnetic bearing. Huang and Lin [15] used a fuzzy control method to conduct theoretical and experimental research on unbalanced vibration control of conical electromagnetic bearing. Jiang and Zmood [16] designed a controller based on Ho for self-excitation and external interference. Electromagnetic dampers have the advantages of noncontact, no mechanical friction and wear, no lubrication, long service life, and controllable stiffness and damping. Kasarda et al. [17] applied the electromagnetic damper to the active control of subsynchronous resonance of high-speed single-disk rotor system, which reduced the resonance amplitude by $93 \%$. Nonami et al. applied the electromagnetic damper to the vibration control of the flexible rotor shaft. The control signal of the damper was provided by the analog controller, which effectively reduced the resonance peak of the flexible rotor shaft. Elbuken et al. [18] applied the electromagnetic damper to the vibration control of the rotating suspension and effectively reduced the vibration of the rotating suspension by exerting control force on the rotating suspension through the electromagnetic damper. Using the idea of finite element model and considering the influence of meshing error, Guan et al. $[19,20]$ established the coupled vibration model of the gear transmission system with bending and torsion and deduced the transmission function of the vibration from the gear excitation to the gearbox body, which laid a foundation for the vibration control of the rear gear transmission system. According to the criteria of modal control force and energy consumption, Guan evaluated four different ways of actuator installation in gearbox vibration active control system. The results show that the actuator is connected by extra bearings on the shaft in the best way and is more convenient to install. In the research of gear vibration, many scholars [21-23] also adopt this actuator installation method.
Montague et al. [24] as early as the active control method used in gear vibration control in 1994, they adopt the method of feedforward control needed for the inhibition of gear vibration control was deduced, by manual adjustment of phase shift amplifier in the experiment to adjust the voltage signal of driving voltage actuator, experimental results show that the meshing frequency is $4500 \mathrm{~Hz}$, with $75 \%$ of vibration attenuation. Subsequently, Sutton et al. [7] clamped the three magnetostrictive actuators on the support and controlled the vibration of the gear of the helicopter transmission in the frequency range of $250-1250 \mathrm{~Hz}$ to minimize the vibration kinetic energy of the supporting rod. Rebbechi et al. [25] adopt the feedforward controller to adjust the phase and amplitude of the control force to realize the vibration control of the gearbox box body. The experiment shows that the vibration at the meshing fundamental frequency, double frequency, and triple frequency of the gearbox and the radiation noise at the meshing fundamental frequency is greatly reduced. Chen and Brennan's [26] simple gear mesh model has set up the control needed to control the size of the torsional vibration being deduced, based on the nonlinear system design of the adaptive controller to control the harmonic frequency. The experiment showed that stiffness modulation factor is proportional to the load on the gear,and the torsional vibration damping is about $7 \mathrm{~dB}$ at meshing frequencies of $150-350 \mathrm{~Hz}$. Guan et al. [27] proposed a direct hybrid adaptive control method based on the Lyapunov stability theorem to simultaneously adjust feedback gain and feedforward gain to control gear vibration, and the results showed that this method was not sensitive to gear meshing frequency error. Li et al. [28, 29] installed the actuator on the gear shaft with additional support bearings, combined with the phase-locked loop for frequency estimation of reference signals, and used the filtered LMS algorithm to control the gear vibration. After that, many scholars have improved the filtering LMS algorithm and applied it to active vibration control and achieved good control results [30-39]. Wu and Lin [40] used a digital processor (DSP) to combine three different control algorithms to form a hybrid controller to control the vibration of the gearbox, but it was too complex to be applied in practice. Li et al. [29], based on frequency estimation technology, presented an improved filtering LMS algorithm that is used to control the vibration of the gearbox. To avoid out-of-band overadjustment, an integrated adaptive linear enhancer is also used.

Most of the above researches on vibration control of gearbox adopt a single gear transmission system, so singleinput and single-output control methods are adopted. In this paper, a two-stage gearbox is taken as the controlled object, and there is two gear meshing excitation in the system. To achieve global vibration suppression of the system, multiple sensors are needed to capture the dynamic vibration of the structure and multiple actuators to suppress the energy generated by excitation [41-43]. Therefore, this paper will adopt a multichannel control method $[44,45]$ to control the vibration of the two-stage gear transmission system actively. As a common model, the traditional FxLMS algorithm has been widely studied and applied in vibration control in 
recent years, but it is difficult to achieve good performance in convergence speed and convergence accuracy. To solve the problems existing in traditional FxLMS algorithms, a multichannel FxLMS algorithm with variable step size is proposed in this paper. The algorithm accelerates the convergence speed in the initial stage of convergence, improves the convergence accuracy in the steady-state adaptive stage, and makes the system have certain robustness [46].

Traditional vibration control methods such as modal control, pole assignment, and optimal control are based on the precise model of controlled structure, but the gear transmission system is a vibration system with serious uncertainty and difficult to accurately model. It is difficult to design a steady feedback system to achieve the desired control performance by using traditional control methods. However, the adaptive control method is less dependent on prior knowledge and does not depend on specific models, so it is an ideal choice to apply the adaptive control method to the active control of gear vibration.

\section{Establishment of the Two-Stage Transmission Gearbox Model}

UG software can get different specifications of parts by modifying the parameters. It only needs to input some basic parameters of gears, such as tooth number, modulus, pressure angle, and tooth surface width. UG software can automatically generate the required gear model. This method can also be used for gear shaft and bearing, which greatly improves design efficiency. The main parameters of the gears in the gearbox are calculated by the formula derivation [47]. The basic data of gears are shown in Table 1.

The shaft is designed according to the size of the gear. The main radial size of the shaft is shown in Figure 1. Among them, (a) is the high-speed shaft and low-speed shaft; (b) is the intermediate shaft. The size of the box is determined according to the size of the shaft and the size of the gear. The internal size of the box is $282 \mathrm{~mm} \times 135 \mathrm{~mm} \times 270 \mathrm{~mm}$. Use UG to generate a three-dimensional model according to the designed size, and the established three-dimensional model is shown in Figure 2. The motor is an adjustable speed motor, which can adjust the speed of the gearbox in a large range. The load is a magnetic powder brake; on the one hand, it can adjust the load, allowing a more comprehensive analysis of the dynamic characteristics of gear load. On the other hand, it could make gear mesh closer by applying a load. Due to gear wear and insufficient precision, there will be gaps between the gear components. Under low or light load conditions, the gear meshing may swing back and forth, which will have a certain impact on the acquired signal. This effect can be reduced by applying a load.

The details of the active control structure inside the gearbox are shown in Figure 3. The active control structure is composed of an actuator bracket, a piezoelectric actuator, an antiload bar, and a support bearing. The bottom of the bracket is bolted to the wall of the box, and one end of the actuator is clamped with the top sleeve. The other end of the actuator is connected with the antiload bar, and the antiload bar is fixed on the support bearing. The antiload bar is a slender shaft with a certain degree of flexibility for overload protection. Besides, to improve the control accuracy, the direction of the control force output of the piezoelectric ceramic actuator is parallel to the direction of the meshing line of the gear.

The 3D model of the two-stage gearbox was imported into ADAMS, and the virtual prototype model was constructed by adding constraints. The functional expression of contact force is

$\operatorname{MAX}\left\{0, K\left(q_{0}-q\right)^{e}-C \times \frac{d q}{d t} \times \operatorname{STEP}\left(q, q_{0}-d, 1, q_{0}, 0\right)\right\}$,

where $K$ is the stiffness coefficient, $q_{0}$ is the reference collision distance of two contact objects, $q$ is the actual collision distance of two contact objects, $e$ is the index in the rigidity, $C$ is the damping rate, and $d$ is the distance that the damping rate reaches the maximum.

The gear is made of no. 45 steel, and the bearing is made of type 6003 deep groove ball bearing. For the contact collision between the gears, the contact collision parameters between the bearing ball and the inner and outer rings are set as shown in Table 2.

Add the constraints of each component, set the speed on the input shaft, and apply load on the output shaft, and the virtual prototype of the two-stage gear transmission system can be obtained, as shown in Figure 4.

To verify the usability of the virtual prototype and provide a theoretical basis for vibration active control joint simulation, dynamic simulation in ADAMS, first set the multistage gearbox virtual prototype input speed to $2540 \mathrm{rpm}$ and the load to $1 \mathrm{~N} \cdot \mathrm{m}$. At this time, the meshing fundamental frequency of low-speed shaft gear is $500 \mathrm{~Hz}$, and that of highspeed shaft gear is $804 \mathrm{~Hz}$. The simulation time is set as $0.5 \mathrm{~s}$, and the simulation step length is 0.0001 for simulation verification. Figures 5(a) $-5(d)$ show the vibration acceleration of the low-speed axis and the high-speed axis in the time domain and frequency domain, respectively.

\section{Description of the Improved FxLMS Algorithm}

3.1. Traditional FxLMS Algorithm. The online identification method of secondary channels is an additional random noise method first proposed by Eriksson and Allie [48], as shown in Figure 6. $P(n)$ is the transfer function from the primary source to the control point. $S(n)$ is a transfer function of the secondary path from the actuator to the control point and is a very complex electro-acoustic coupling system, which is mainly composed of D/A conversion, loudspeaker, secondary acoustic channel, and A/D conversion. $X(n)$ is the reference signal. $E(n)$ refers to the residual vibration response signal detected by the error sensor at the control point.

Random noise $v(n)$ is used as the input of the secondary channel adaptive online identification filter $S^{\prime}(n)$. When the identification filter converges, $S^{\prime}(n)$ can uniquely converge to $S(n)$. In the adaptive control process, $S^{\prime}(n)$ can be used as an 
TABLE 1: Gears at all levels.

\begin{tabular}{lcccc}
\hline Part name & Tooth number & Tooth surface width $(\mathrm{mm})$ & Modulus $(\mathrm{mm})$ & Pressure angle $\left(^{\circ}\right)$ \\
\hline High-speed shaft gear & 19 & 25 & 2.0 & 20 \\
Low-speed shaft gear & 35 & 25 & 2.0 & 20 \\
Middle shaft big gear & 37 & 20 & 2.0 & 20 \\
Middle shaft small gear & 23 & 30 & 2.0 & 20 \\
\hline
\end{tabular}

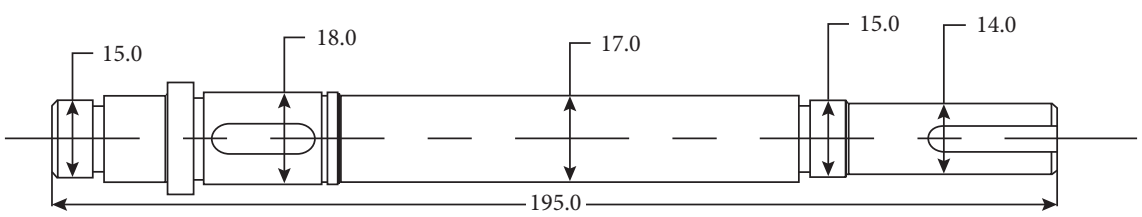

(a)

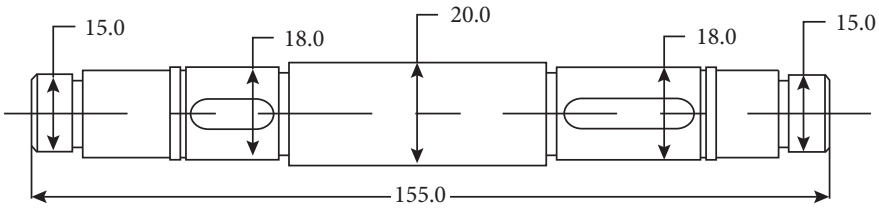

(b)

FIGURE 1: Dimension drawing of the shaft.

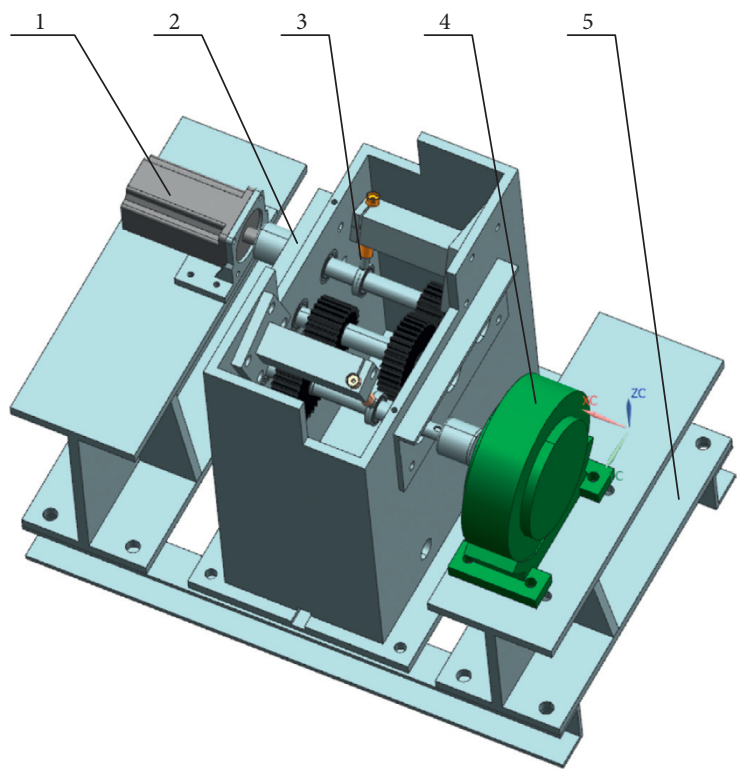

FIGURE 2: Gear transmission system with a built-in piezoelectric actuator. 1: motor, 2: gear box, 3: active control structure, 4: magnetic powder brake, and 5: base.

estimated transfer function of the secondary channel $S(n)$. However, this method will add random noise to the input of the actuator $y(n)$ and cause additional vibration of the control point through the secondary channel, and the vibration cannot be eliminated in the whole identification process of the secondary channel.

The calculation process of the algorithm is as follows:

$$
\begin{aligned}
\mathbf{e}(n) & =\mathbf{d}(n)+\mathbf{v}^{\prime}(n)+y^{\prime}(n), \\
\mathbf{e}_{s} & =\mathbf{e}(n)-\mathbf{v}(n) \times \mathbf{s}^{\prime}(n) .
\end{aligned}
$$

According to the LMS algorithm, the weight iteration of online identification of secondary channels can be expressed as

$$
\mathbf{s}^{\prime}(n+1)=\mathbf{s}^{\prime}(n)+\mu_{s} \mathbf{v}(n) \mathbf{e}^{\prime}(n),
$$

where $\mu_{s}$ is the step size of filter $S^{\prime}(n)$, and

$$
\begin{aligned}
\mathbf{s}^{\prime}(n) & =\left[s_{0}, s_{1}, \ldots, s_{M-1}\right] \\
\mathbf{v}(n) & =[v(n), v(n-1), \ldots v(n-M+1)]^{\mathrm{T}},
\end{aligned}
$$




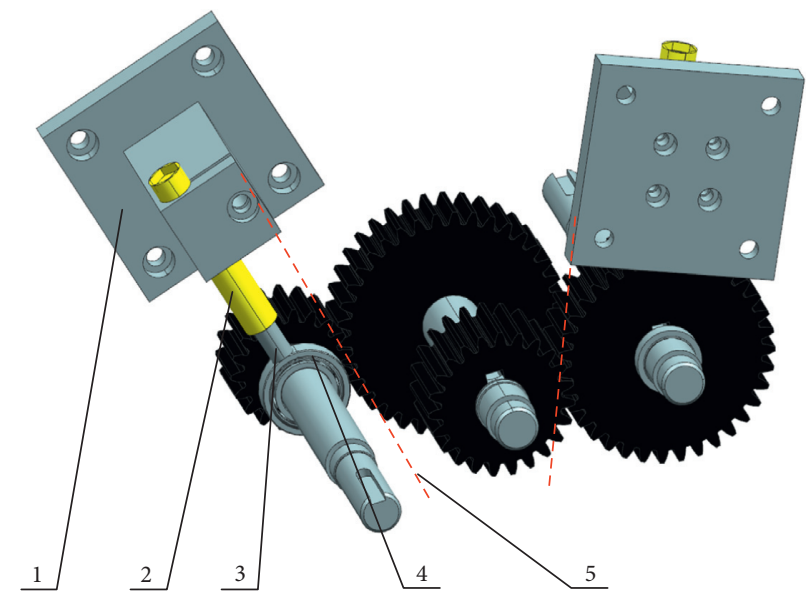

FIGURE 3: Internal details of active control structure. 1: actuator support, 2: piezoelectric actuator, 3: antiload rod, 4: support bearing, and 5: meshing line.

TABLE 2: Gears at all levels.

\begin{tabular}{lcc}
\hline Part name & Gear & Ball bearing \\
\hline Stiffness coefficient $K$ & $9.16 \times 10^{5} \mathrm{~N} / \mathrm{mm}^{3 / 2}$ & $1.644 \times 10^{5} \mathrm{~N} / \mathrm{mm}^{3 / 2}$ \\
Stiffness force index $e$ & 1.5 & 1.5 \\
Damping ratio $C$ & $30 \mathrm{~N} \cdot \mathrm{S}^{-1} / \mathrm{mm}$ & $30 \mathrm{~N} \cdot \mathrm{S}^{-1} / \mathrm{mm}$ \\
The damping rate reaches the maximum distance & $0.1 \mathrm{~mm}$ & $0.05 \mathrm{~mm}$ \\
Coefficient of dynamic friction & 0.05 & 0.0036 \\
Coefficient of static friction & 0.08 & 0.05 \\
\hline
\end{tabular}

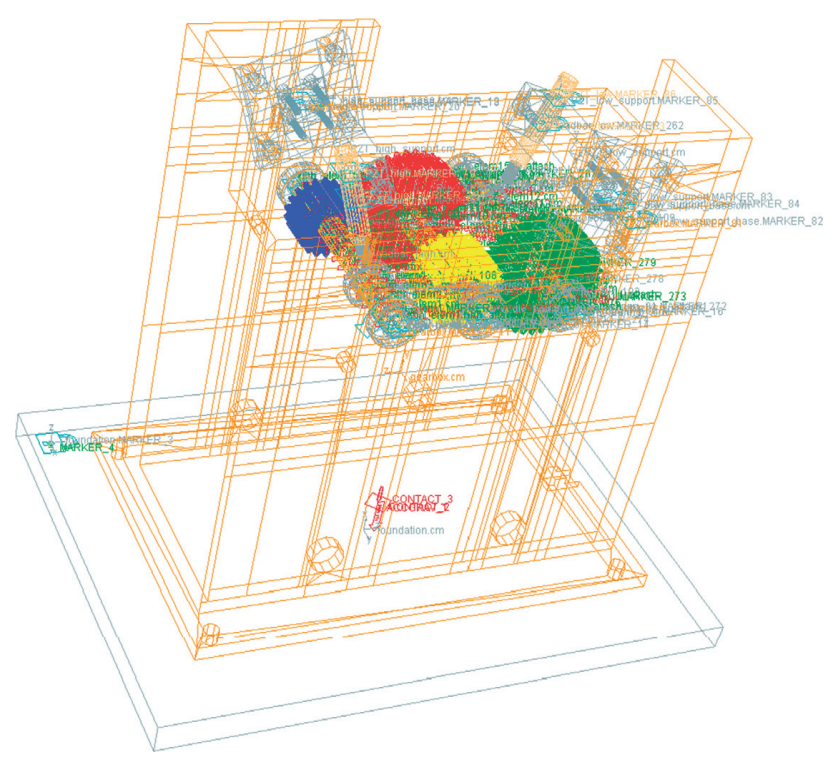

FIGURE 4: Overall diagram of the ADAMS virtual prototype. 


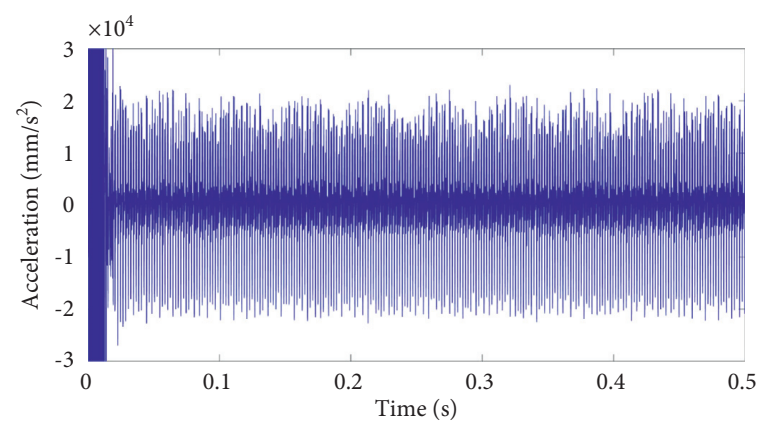

(a)

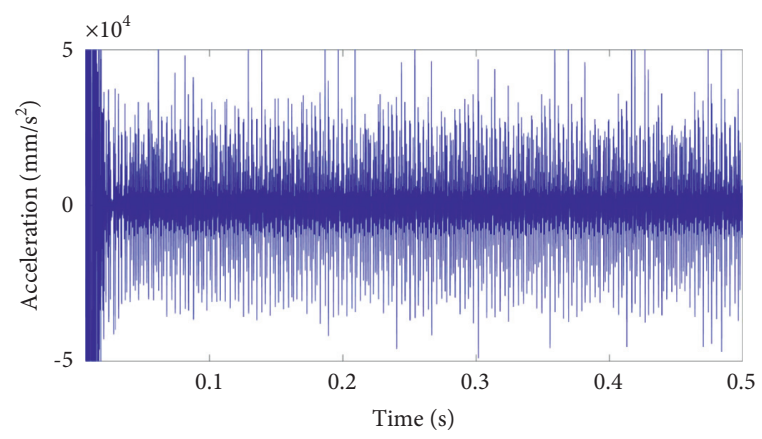

(c)

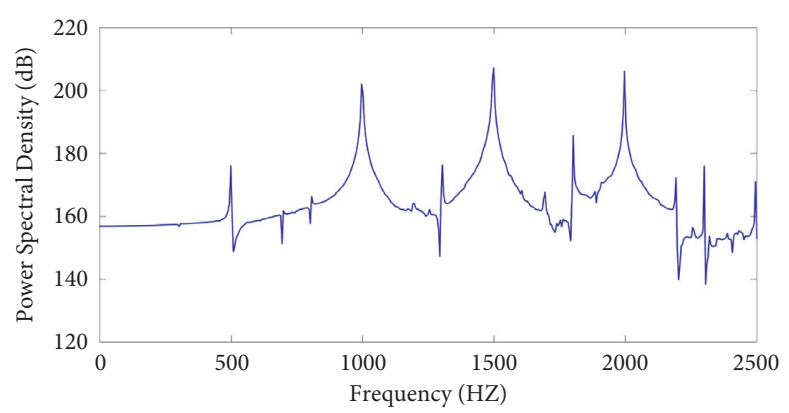

(b)

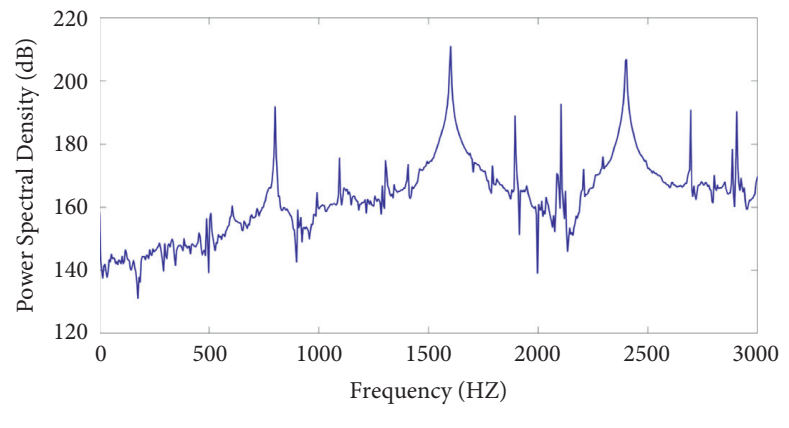

(d)

Figure 5: Diagram of vibration acceleration in the time domain and frequency domain. (a) Time domain and (b) frequency domain of the low-speed shaft gear. (c) Time domain and (d) frequency domain of the high-speed shaft gear.

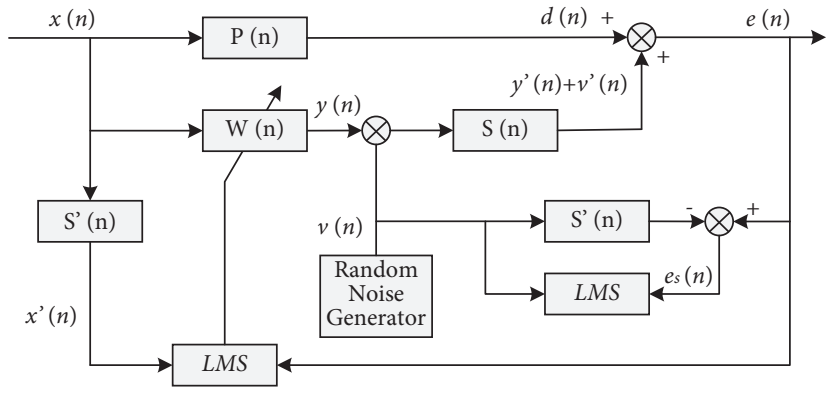

FIGURE 6: Eriksson's secondary channel flow diagram.

where $M$ is the length of filter $S^{\prime}(n)$.

At this time, the weight update of the FxLMS algorithm is expressed by the following formula:

$$
\begin{aligned}
\mathbf{w}(n+1) & =\mathbf{w}(n)+\mu \mathbf{x}^{\prime}(n) \mathbf{e}(n) \\
\mathbf{w}(n) & =\left[w_{0}, w_{1}, \ldots w_{N-1}\right]^{\mathrm{T}} \\
\mathbf{x}^{\prime}(n) & =\left[x^{\prime}(n), x^{\prime}(n-1), \ldots, x^{\prime}(n-N+1)\right],
\end{aligned}
$$

where $\mu$ is the step size of the FxLMS algorithm and $N$ is the length of the weight $W(n)$ of the FxLMS algorithm.

The traditional FxLMS algorithm updates iteratively with a fixed step size. When the step size factor is larger, the convergence rate is faster in the early stage, but in the steadystate adaptive stage, the step size is too large, and the oscillation occurs, resulting in a large error. On the contrary, when the step size factor is small, the steady-state error is small, but the convergence rate in the early stage will decrease greatly. Moreover, the traditional FxLMS algorithm mainly studies the single-channel problem. With the increasing degree of mechanical complexity, it is difficult to meet the control requirements of a single channel.

\subsection{Improved Multichannel Variable-Step-Size FxLMS} Algorithm. To solve the problem of the traditional fixed step size algorithm, many kinds of research have been made on the variable-step-size LMS algorithm. In this paper, three classical variable-step-size LMS are compared. Based on the variable-step-size LMS algorithm based on the sampling function, a certain change is made to the form of the variable-step-size LMS algorithm. In the case of little impact on the convergence rate, the steady-state error is smaller, and it has a better anti-interference ability. 
The mechanism of variable-step-size LMS algorithm is a function model between step size factor and error. Three typical function models are as follows.

Step factor $\mu(n)$ is the Sigmoid function of error $e(n)$, as shown in the following equation:

$$
\mu(n)=\alpha\left\{\frac{1}{1+e^{(-\beta|e(n)|)}}-0.5\right\} .
$$

Step factor $\mu(n)$ is the tongue function of error $e(n)$, as shown in the following equation:

$$
\mu(n)=\alpha\left\{1-\frac{1}{\beta e^{2}(n)+1}\right\} .
$$

Step factor $\mu(n)$ is the sampling function of error $e(n)$, as shown in the following equation:

$$
\mu(n)=\alpha\left\{1-\frac{\sin (\beta \times e(n))}{\beta \times e(n)}\right\},
$$

where $\alpha$ and $\beta$ take the same parameters as 4 and 8 , respectively, to obtain the nonlinear curve of step factor and error signal of the above algorithm.

From Figure 7, we can see that compared with the sigmoid function and tongue function, the LMS algorithm based on the sampling function has a larger step size in the early stage, so its convergence rate is relatively fast. In the steady-state adaptive stage, the steady-state error is small because of the smaller $\mathrm{d} \mu / \mathrm{d} e(n)$ value. On this basis, the function is further improved.

$$
\mu(n)=\alpha\left\{1-\frac{\sin (\beta \times e(n) \times e(n-1))}{\beta \times e(n) \times e(n-1)}\right\},
$$

where the values of $\alpha$ and $\beta$ are still 4 and 8; the curves are compared in Figure 8.

It can be seen from Figure 8 that the improved LMS algorithm based on sampling function does not reduce the step size significantly in the early stage but significantly reduces the step size in the steady-state adaptive stage, which will lead to a decrease in the convergence rate, but significantly improves the convergence accuracy. Moreover, the autocorrelation value $e(n) \times e(n-1)$ of the error signal is used to adjust the step factor in the functional relation between the step factor and the error so that the step factor has the anti-interference ability.

The iterative formula of the improved LMS adaptive algorithm based on the variable step size of the sampling function is as follows:

$$
\begin{aligned}
e(n) & =d(n)-X^{T}(n) W(n), \\
W(n+1) & =W(n)+2 \mu(n) e(n) X(n), \\
\mu(\mathrm{n}) & =\alpha\left\{1-\frac{\sin (\beta \times e(n) \times e(n-1))}{\beta \times e(n) \times e(n-1)}\right\} .
\end{aligned}
$$

From (10), we can get

$$
d(n)=X^{T}(n) W(n)+e(n) .
$$

According to the principle of adaptive filtering, the above equation can be rewritten as

$$
d(n)=X^{T}(n) W^{*}(n)+v(n),
$$

where $W^{*}(n)$ is the optimal weight coefficient of the filter, and the mean value of $v(n)$ is 0 , which is unrelated to the input signal.

Substitute (12) into equation (10) to get

$$
\begin{aligned}
e(n) & =v(n)+X^{T}(n) W^{*}(n)-X^{T}(n) W(n) \\
& =v(n)+X^{T}(n)\left(W^{*}(n)-W(n)\right) \\
& =v(n)+X^{T}(n) \Delta W(n),
\end{aligned}
$$

where $\Delta W(n)$ is the weight coefficient deviation.

So, we get

$$
\begin{aligned}
e(n) e(n-1)= & v(n) v(n-1)+v(n) X^{T}(n-1) \Delta W(n-1) \\
& +X^{T}(n) \Delta W(n) v(n-1) \\
& +X^{T}(n) \Delta W(n) X^{T}(n-1) \Delta W(n-1) .
\end{aligned}
$$

According to the fact that $v(n)$ is a Gaussian white noise signal, its correlation is poor, that is, $E[v(n) v(n-1)]=0$, and is not related to the input signal $X(n)$, the following can be obtained:

$E[e(n) e(n-1)]=E\left[X^{T}(n) \Delta W(n) X^{T}(n-1) \Delta W(n-1)\right]$.

From equation (15), we can see that in the function of step factor and error signal obtained by the improved LMS adaptive algorithm based on variable step size of sampling function, the influence of noise signal is eliminated, so the algorithm is not affected by noise signal and has a strong anti-interference ability.

The improved LMS algorithm is applied to the multichannel active vibration control system. The improved FxLMS algorithm is the multichannel variable step size FxLMS algorithm. The schematic diagram of the active control structure is shown in Figure 9, where $x(n)$ represents the reference signal, $S$ represents the secondary channel between all actuators and sensors, $W$ represents the channel variable step FxLMS algorithm controller in the multichannel vibration control system, and $V$ represents the white noise output to the secondary channel. Suppose the system has $J$ active controllers, $K$ sensors, the reference signal is written as $x(n)$, and the FxLMS controller $W$ is written as

$$
W=\left[w_{1}, w_{2}, \ldots, w_{j}\right]^{T},
$$

where $w_{j}$ is the weight vector of the $j$ th controller, which is to write the ownership value coefficient in the FxLMS algorithm as a weight vector.

The multichannel active vibration control system has $J \times K$ secondary channels; secondary channel $S$ can be written as 


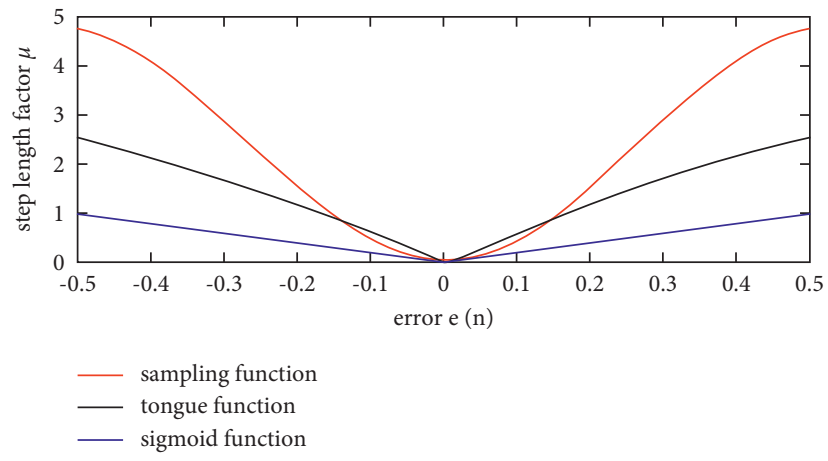

FIgURe 7: Step factor and error signal curve contrast diagram.

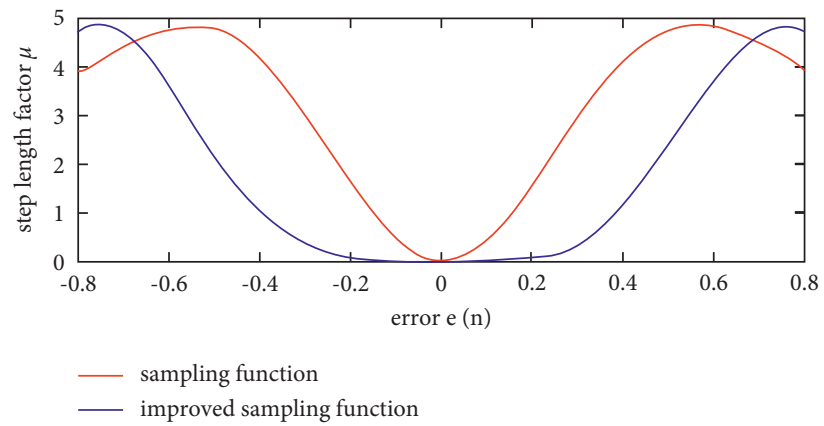

Figure 8: Comparison diagram of sample function curve and improved sample function curve.

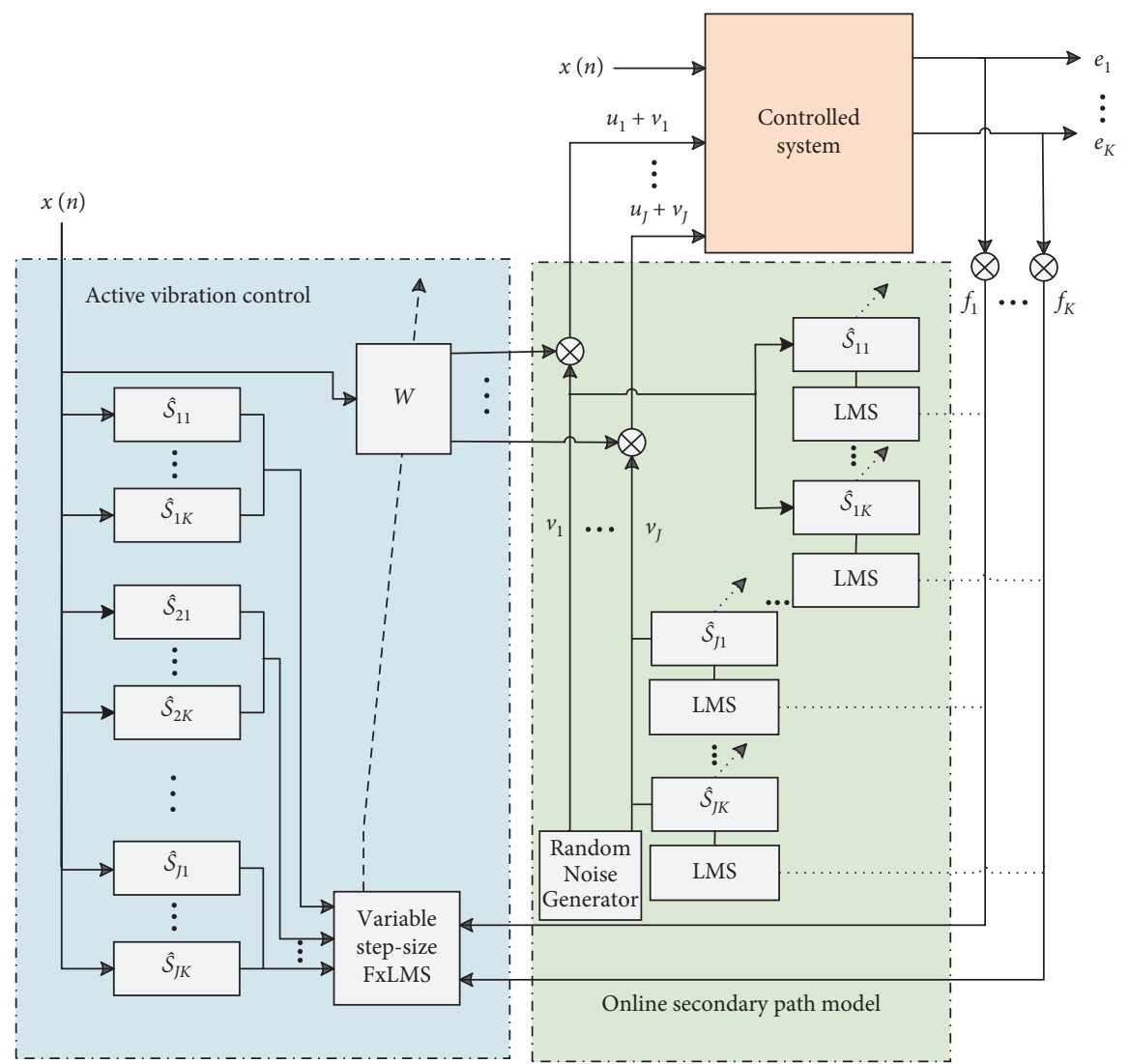

FIGURE 9: Multichannel variable-step-size FxLMS algorithm active vibration control structure. 


$$
S(n)=\left[\begin{array}{ccc}
\mathrm{s}_{11}(\mathrm{n}) & \cdots & \mathrm{s}_{1 \mathrm{~K}}(\mathrm{n}) \\
\vdots & \ddots & \vdots \\
\mathrm{s}_{\mathrm{J1}}(\mathrm{n}) & \cdots & \mathrm{s}_{\mathrm{JK}}(\mathrm{n})
\end{array}\right]
$$

where $\mathrm{s}_{\mathrm{IK}}(\mathrm{n})$ represents the secondary channel between the $j$ th active actuator and the $k$ th sensor. $s_{J K}^{\prime}(n)$ represents the filter coefficient identified using the secondary channel between the $j$ th active actuator and the $k$ th sensor.

\section{The Cosimulation}

Combined with the multichannel FxLMS algorithm structure in Figure 10 and the active control structure of the twostage gearbox in Figure 2, the active vibration control system of the gearbox is designed as shown in Figure 10 below. The vibration caused by excitation and the gear pair is the control target. $S_{1}(z)$ and $S_{2}(z)$, respectively, represent two secondary channels. To eliminate the influence of secondary channels, corresponding models $\widehat{S}_{1}(z)$ and $\widehat{S}_{2}(z)$ are introduced into the control system to filter the input signals of the controller. In adaptive active vibration control, the selection of reference signals has a great influence on the control effect. To obtain the reference signals with high correlation with the vibration of the gear system, the frequency estimation of the vibration signals collected in real time is carried out through the second-order IIR adaptive notch filter [49] to obtain the meshing frequency of the gear pair and then synthesize the reference signals online.

Through simulation, the effectiveness of the improved FxLMS algorithm in the application of two-gearbox vibration active control is verified. In Simulink to build vibration active control system, its core is the improved FxLMS adaptive filter, due to the multiple-input multiple-output filter, the Level-2 function improved FxLMS algorithm, the adaptive trap of reference signal synthesizer using the same Level-2 function to carry on the design, use of FIR filter structure simulation of the secondary channel, connect the controller, the reference signal synthesizer, and the secondary channel model, and get the vibration active control system. The virtual prototype model of the gear transmission system in ADAMS was imported into Simulink as a mechanical module, which was connected with the control system to obtain the active vibration control cosimulation model of gear transmission integrated with the mechanical system and the control system, as shown in Figure 11.

The input speed of the gearbox is $2540 \mathrm{rpm}$. The meshing frequency of the high-speed shaft gear pair is $800 \mathrm{~Hz}$ and the meshing frequency of the low-speed shaft gear pair is $500 \mathrm{~Hz}$. The load is $1 \mathrm{~N} \cdot \mathrm{m}$. Set the simulation parameters as follows: the adaptive filter order as the controller is set to 80 , the step size factor of the algorithm adopts the variable-steplength factor based on the sampling function, and the sampling frequency is selected as $10 \mathrm{kHz}$. Joint simulation is carried out, and the simulation results are shown in Figure 12.

Figures $12(a)$ and $12(\mathrm{c})$ show that compared with the traditional FxLMS algorithm, the improved FxLMS algorithm has a faster convergence rate and a smaller steady-state error. In Figure 12(a), the FxLMS control system reaches stability after about $0.15 \mathrm{~s}$, while the improved FxLMS control system reaches stability after about $0.07 \mathrm{~s}$. In Figure 12(c), the FxLMS control system reaches stability after about $0.12 \mathrm{~s}$, while the improved FxLMS control system reaches stability after about $0.08 \mathrm{~s}$. Moreover, it can be seen from Figures 12(a) and 12(c) that the improved FxLMS control system has a smaller vibration acceleration after stabilization is achieved.

Figures 12(b) and 12(d) show that the suppression of vibration by the active vibration control system is mainly at the 2nd and 3rd harmonics. In Figure 12(b), the vibration reduction of the FxLMS control system at the 2nd harmonic $1000 \mathrm{~Hz}$ and the $3 \mathrm{rd}$ harmonic $1500 \mathrm{~Hz}$ is $10 \mathrm{~dB}$ and $14 \mathrm{~dB}$, respectively. The vibration reduction of the improved FxLMS control system at $1000 \mathrm{~Hz}$ and $1500 \mathrm{~Hz}$ is $23 \mathrm{~dB}$ and $31 \mathrm{~dB}$, respectively. In Figure 12(d), the vibration reduction of the FxLMS control system at $1608 \mathrm{~Hz}$ and $2412 \mathrm{~Hz}$ of the second- and third-order harmonics is $17 \mathrm{~dB}$ and $28 \mathrm{~dB}$, respectively. The vibration reduction of the improved FxLMS control system at $1608 \mathrm{~Hz}$ and $2412 \mathrm{~Hz}$ is $24 \mathrm{~dB}$ and $37 \mathrm{~dB}$, respectively. It is further proved that compared with the traditional FxLMS algorithm, the improved FxLMS algorithm has a smaller steady-state error.

\section{Design and Verification of Experiments}

The experimental platform of the active vibration control system of the gearbox system can be divided into three parts, namely, the gear transmission system, the vibration measurement processing system, and the active control system. The established platform is shown in Figure 13.

The gear transmission system consists of a DC motor, motor governor, coupling, gear transmission part, and magnetic powder brake. The gear transmission part is composed of two pairs of meshing gears, the modulus is 2 , the pressure angle is $20^{\circ}$, the number of teeth of high-speed shaft meshing gear is 19 and 37, respectively, and the number of teeth of low-speed shaft meshing gear is 23 and 35. Adjustable speed motor speed range is of $0-1800 \mathrm{rpm}$. The two couplings are, respectively, connected with the motor and the high-speed shaft, the magnetic powder brake, and the low-speed shaft. Magnetic powder brake can provide $0-15 \mathrm{~N} \cdot \mathrm{m}$ torque.

The vibration measurement processing systemis used to detect the vibration signal of the gearbox and the error signalinput to the controller. The acceleration sensor is used to collect the signalof the casing, and the collected signal is displayed in real time with theanalysis software DASP-V11 and is input to the controller as a calculatederror signal to calculate and output the control signal.

The active control system includes a controller, a piezoelectric actuator, a piezoelectric actuator power supply, and an actuator clamp. For the control system, this paper selects the Speedgoat real-time simulation system as the control system of active vibration control and establishes a semiphysical simulation control platform. The Speedgoat real-time simulation system provides a MATLAB/Simulink driver module that converts the algorithm control system 


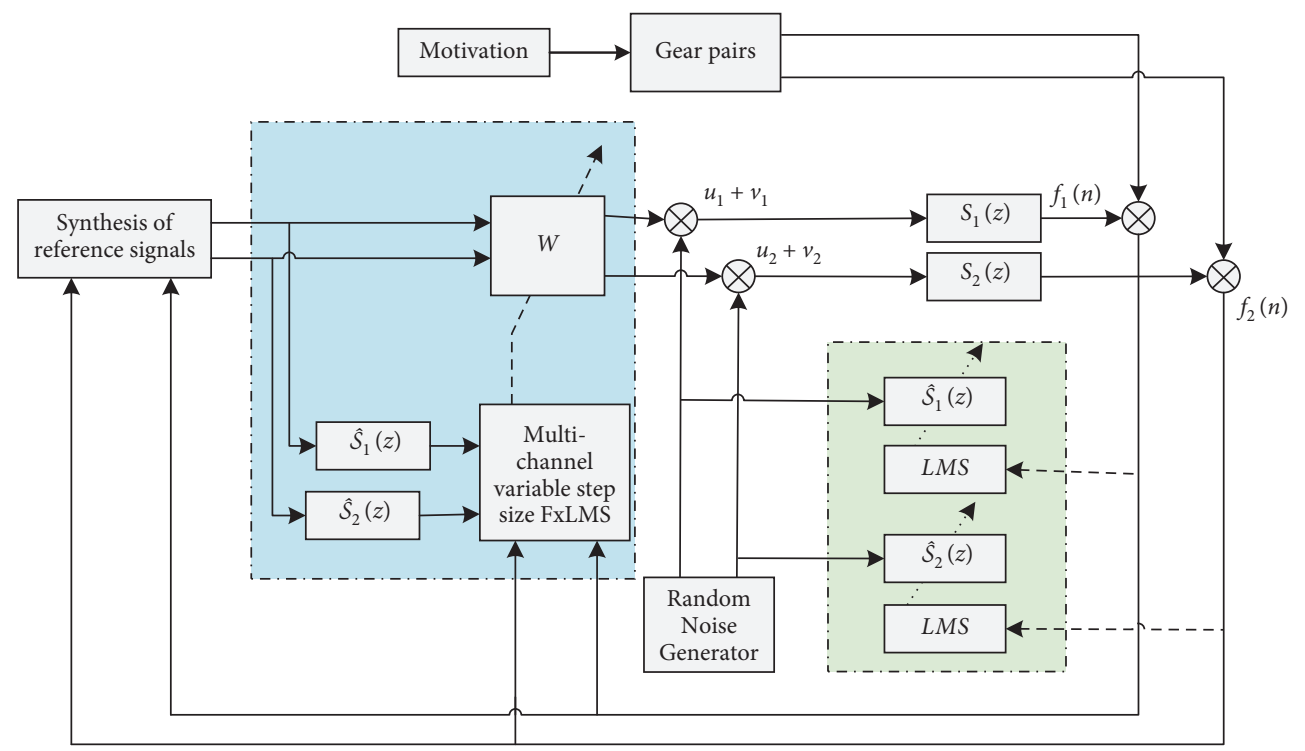

FIGURE 10: Multiharmonic vibration active control of the two-stage gear transmission system.

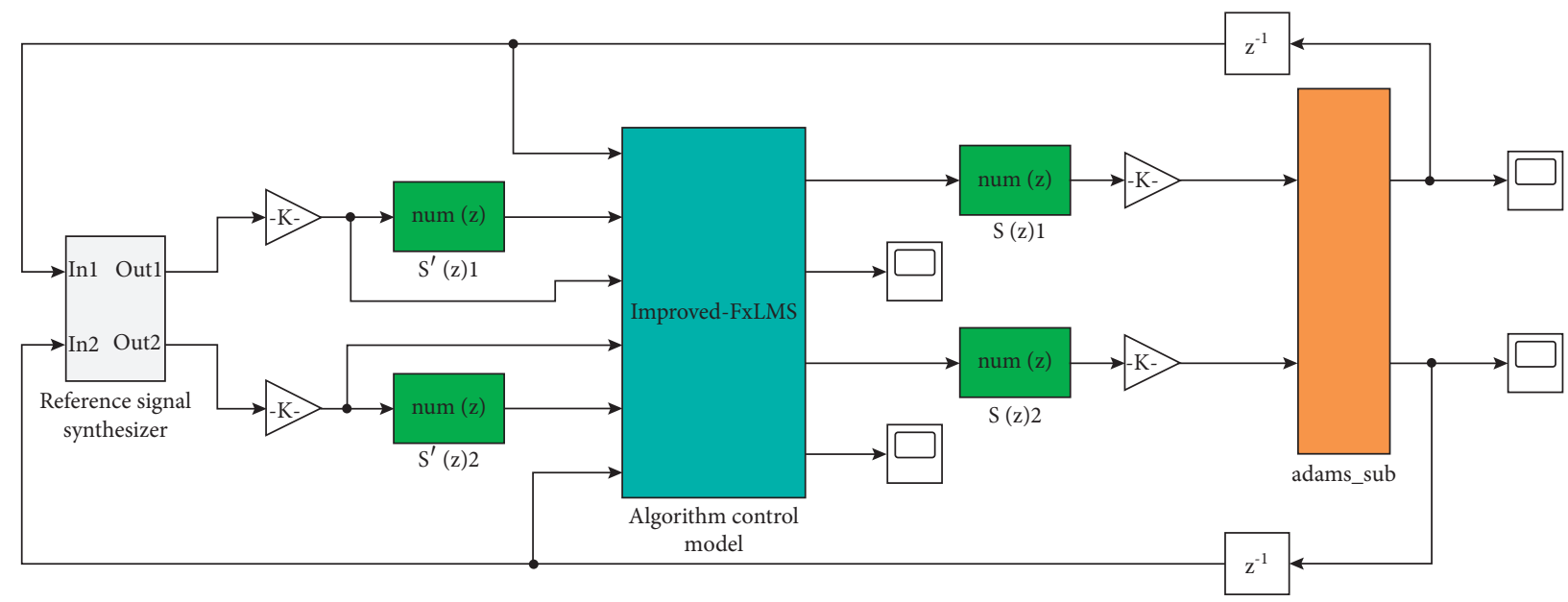

FIgURE 11: Active vibration control joint simulation system of the gearbox.

established on Simulink into the required $\mathrm{C}$ code and transmits the generated object code to the processor, which calculates the voltage signal of the piezoelectric actuator and controls the piezoelectric actuator.

To verify the effectiveness of the proposed multichannel active vibration control structure for the vibration control of the gear transmission system, the proposed active control algorithm was programmed, compiled, and downloaded to the real-time target machine as the controller of the active control system on the MATLAB/Simulink platform, and the multichannel variable-step-size FxLMS algorithm was adopted in this paper. To ensure the effectiveness of the control system, the sampling time of the controller is set to $0.0001 \mathrm{~s}$. The motor speed was adjusted to $1200 \mathrm{rpm}$, the load was adjusted to $1 \mathrm{NM}$, and the active vibration control was started. The vibration signals of the gearbox body were collected through the acceleration sensor, as shown in Figure 14. The vibration signals before and after the control were Fourier transformed to obtain the vibration frequency domain control diagram, which was compared with the traditional FxLMS algorithm, as shown in Figure 15. The meshing fundamental frequencies of the low-speed shaft and high-speed shaft are $236 \mathrm{~Hz}$ and $380 \mathrm{~Hz}$, respectively.

It can be seen from the time-domain diagram of vibration control in Figure 14 that the vibration attenuation begins at $8 \mathrm{~s}$ when the control begins, and the convergence is completed at the 12th second, and the vibration attenuation reaches $70 \%$ before the control. As can be seen from the local enlargement of Figure 15, the control effect is obvious at the basic frequency and multiple frequencies of gear meshing. The specific meshing frequency data is shown in Table 3 below. It can be seen from Table 3 that the decay of the meshing frequency of the low-speed shaft is about 3-4 dB, and that of the high-speed shaft is $3-5.5 \mathrm{~dB}$. According to the data in Table 3, it can be calculated that the convergence accuracy has increased by $23 \%-82 \%$.

When the speed is adjusted to $1530 \mathrm{rpm}$, the meshing fundamental frequency of the low-speed shaft and high- 


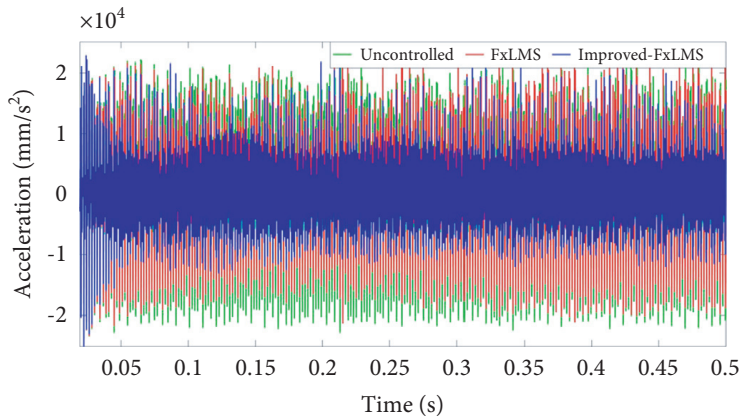

(a)

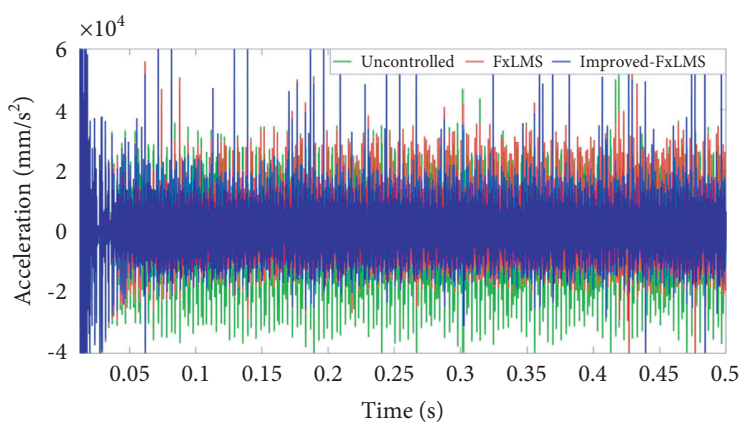

(c)

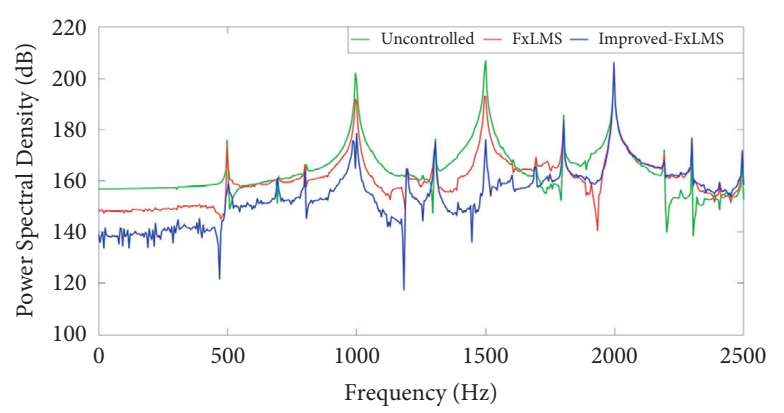

(b)

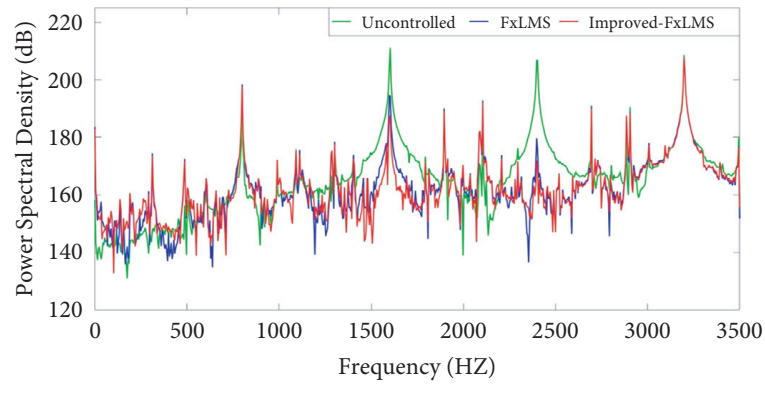

(d)

FiguRE 12: Simulation results of active vibration control. (a) Low-speed shaft time domain, (b) low-speed frequency time domain, (c) highspeed shaft time domain, and (d) high-speed frequency time domain.

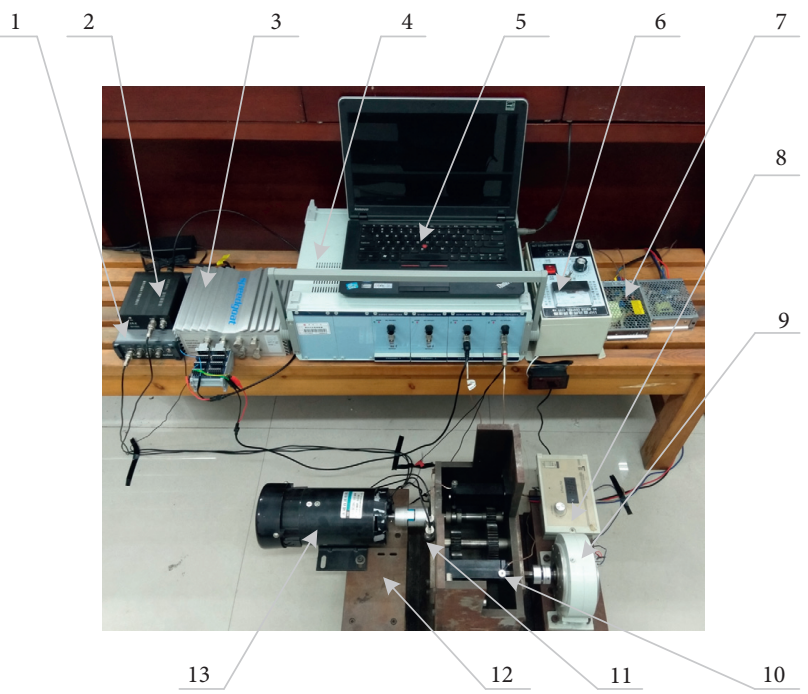

FIgURE 13: Active control test platform for the vibration of the gear transmission system. 1: signal collector, 2: signal conditioner, 3: controller, 4: power amplifier, 5: PC, 6: motor, 7: power, 8: torque adjuster, 9: magnetic powder, 10: piezoelectric actuator, 11: acceleration sensor, 12: multistage gear transmission system, and 13: adjustable speed motor.

speed shaft is $301 \mathrm{~Hz}$ and $485 \mathrm{~Hz}$, respectively. The vibration generated by the gear transmission system is controlled, and the control frequency domain curve is shown in Figure 16. It can be seen from the figure that the attenuation at low-speed shaft meshing frequency is $4.5-5 \mathrm{~dB}$, and the vibration attenuation at high-speed shaft meshing frequency is about 8$9 \mathrm{~dB}$. The specific meshing frequency data is shown in Table 4. According to the data in Table 4, it can be calculated that the convergence accuracy has increased by $36 \%-123 \%$.
Based on the active vibration control results of the gear under two rotating speeds, we can know that the proposed multichannel variable-step-size FxLMS algorithm has an effective suppression effect on the vibration at the high harmonic in the gear transmission system, and the vibration attenuation range is $3-9 \mathrm{~dB}$. It can be seen that the attenuation of the meshing frequency of the high-speed shaft is higher than that of the low-speed shaft. Compared with the traditional FxLMS algorithm, the proposed multichannel 


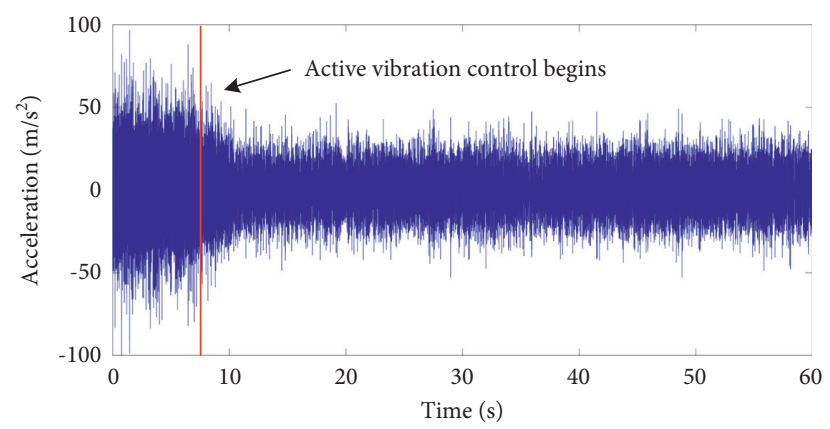

FIgURE 14: Time-domain control of vibration at $1200 \mathrm{rpm}$.

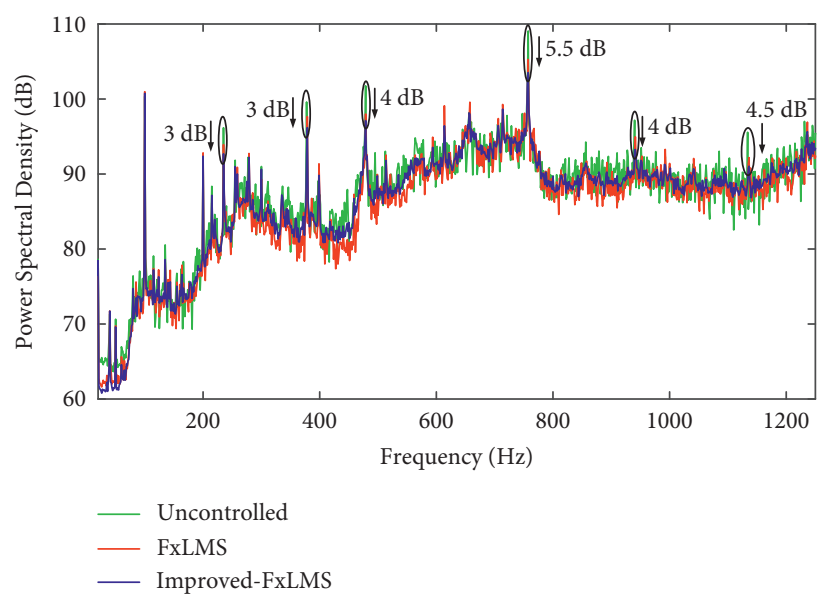

FIGURE 15: Vibration frequency domain control diagram at $1200 \mathrm{rpm}$.

TABle 3: Active vibration control of the gear system at $1200 \mathrm{r} / \mathrm{min}$ and $1 \mathrm{~N} \mathrm{~m}$.

\begin{tabular}{lccc}
\hline Frequency/Hz & & Power spectral density $(\mathrm{dB})$ & \\
& Uncontrolled & FxLMS & Improved FxLMS \\
\hline 236 & 96.17 & 93.92 & 92.68 \\
380 & 99.60 & 97.66 & 96.28 \\
473 & 101.75 & 98.00 & 97.12 \\
760 & 109.07 & 105.27 & 103.51 \\
940 & 97.17 & 94.96 & 93.14 \\
1140 & 95.57 & 92.18 & 91.04 \\
\hline
\end{tabular}

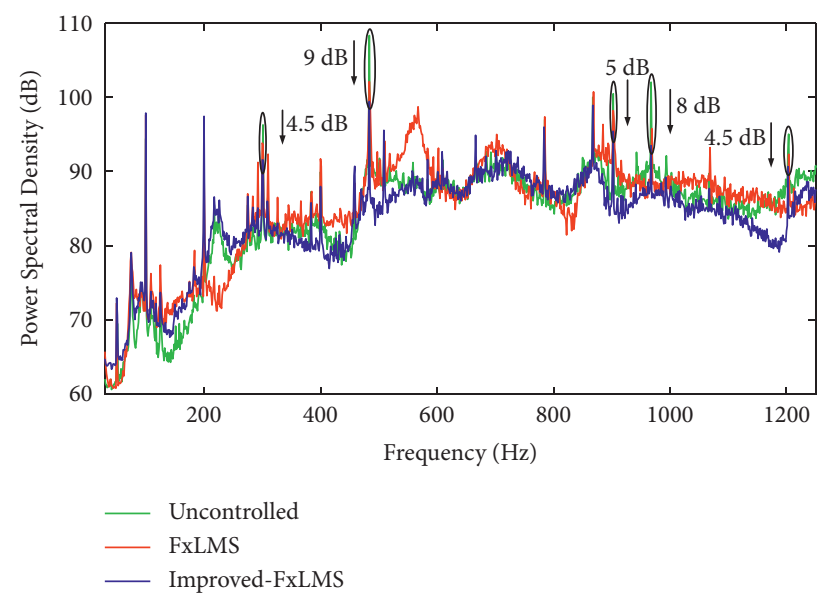

FIGURE 16: Vibration frequency domain control diagram at $1530 \mathrm{rpm}$. 
TABLE 4: Active vibration control of the gear system at $1530 \mathrm{r} / \mathrm{min}$ and $1 \mathrm{~N} \mathrm{~m}$.

\begin{tabular}{lccc}
\hline \multirow{2}{*}{ Frequency $(\mathrm{Hz})$} & \multicolumn{3}{c}{ Power spectral density $(\mathrm{dB})$} \\
& Uncontrolled & FxLMS & Improved FxLMS \\
\hline 301 & 96.27 & 93.82 & 91.54 \\
485 & 108.32 & 102.11 & 99.42 \\
902 & 100.46 & 98.20 & 95.42 \\
970 & 102.03 & 95.77 & 93.48 \\
1203 & 95.03 & 92.32 & 90.65 \\
\hline
\end{tabular}

variable-step-size FxLMS algorithm has a better control effect. The control accuracy can be increased up to $123 \%$.

\section{Conclusion}

In this paper, a novel active vibration control platform based on a piezoelectric actuator is constructed, which is composed of hardware and software such as a two-stage transmission device, control system, signal acquisition, and processing system. The multichannel variable-step-size FxLMS algorithm is used as the controller to control the vibration of the gearbox. Experimental results show that the multichannel variable-step-size FxLMS algorithm is effective for vibration control of the gear system, and its control effect is better than the traditional FxLMS control, which can reduce the vibration by $3-9 \mathrm{~dB}$ at the target. The control accuracy is improved by $23 \%-123 \%$.

\section{Data Availability}

The data used to support the findings of this study are available from the corresponding author upon request.

\section{Conflicts of Interest}

The authors declare that they have no conflicts of interest regarding the publication of this paper.

\section{Acknowledgments}

This work was supported by China National Natural Science Funds (51405169) and the Fundamental Research Funds for the Central Universities (no. ZQN-704).

\section{References}

[1] J. Zhou, "Study on the influence of speed and load on the vibration and noise of reducer," Vibration and Shock, vol. 32, no. 8, pp. 193-198, 2013.

[2] M. Slim Abbes, S. Bouaziz, F. Chaari, M. Maatar, and M. Haddar, "An acoustic-structural interaction modelling for the evaluation of a gearbox-radiated noise," International Journal of Mechanical Sciences, vol. 50, no. 3, pp. 569-577, 2008.

[3] A. Farshidianfar and A. Saghafi, "Global bifurcation and chaos analysis in nonlinear vibration of spur gear systems," Nonlinear Dynamics, vol. 75, no. 4, pp. 783-806, 2014.

[4] L. L. Zhang, R. P. Zhu, G. H. Jin, L. F. Jia, and J. S. Shen, "Vibration and noise analysis of internal excitations of single pair of gears," Journal of Vibration Engineering, vol. 27, no. 6, pp. 915-919, 2014.

[5] J. Wang, H. Xiao, Y. Lv, T. Wang, and Z. Xu, "Detrended fluctuation analysis and hough transform based self-adaptation double-scale feature extraction of gear vibration signals," Shock and Vibration, vol. 2016, no. 4, 9 pages, Article ID 3409897, 2016.

[6] R. Liu, "Study on vibration fault of gear," Journal of China Safety Science, vol. 15, no. 2, pp. 16-18, 2005.

[7] T. J. Sutton, S. J. Elliott, M. J. Brennan, K. H. Heron, and D. A. C. Jessop, "Active isolation OF multiple structural waves ON a helicopter gearbox support strut," Journal of Sound and Vibration, vol. 205, no. 1, pp. 81-101, 1997.

[8] R. Maier, M. Pucher, W. Gembler, and H. Schweitzer, "Helicopter interior Noise Reduction by Active Vibration Isolation with Smart Gearbox Struts," in Proceedings of the INTER-NOISE and NOISE-CON Congress and Conference Proceedings, Lauderdale, FL, USA, January 1999.

[9] I. Pelinescu and B. Balachandran, "Analytical and Experimental Investigations into Active Control of Wave Transmission through Gearbox Struts," Smart Structures and Materials, vol. 3985, 2000.

[10] L. Bouillaut and M. Sidahmed, "Cyclostationary approach and bilinear approach: comparison, applications to early diagnosis for helicopter gearbox and classification method based on hocs," Mechanical Systems and Signal Processing, vol. 15, no. 5, pp. 923-943, 2001.

[11] S. V. Neriya, R. B. Bhat, and T. S. Sankar, "On the dynamic response of a helical geared system subjected to a static transmission error in the form of deterministic and filtered white noise inputs," Journal of Vibration and Acoustics, vol. 110, no. 4, pp. 501-506, 1988.

[12] H. Habermann and B. Brunet, "An active magnetic bearing system," Tribology International, vol. 13, 1980.

[13] K. Zhang and X. Zhang, "A review of unbalance control technology of active magnetic bearings," Chinese Journal of Construction Machinery, vol. 21, no. 8, pp. 897-903, 2010.

[14] E. H. Maslen, G. Schweitzer, H. Bleuler, M. Cole, and P. Keogh, Magnetic Bearings-Theory, Design and Application to Rotating Machinery, Springer, New York, NY, USA, 2009.

[15] S.-J. Huang and L.-C. Lin, "Fuzzy dynamic output feedback control with adaptive rotor imbalance compensation for magnetic bearing systems," IEEE Transactions on Systems, Man and Cybernetics, Part B (Cybernetics), vol. 34, no. 4, pp. 1854-1864, 2004.

[16] Y. Jiang and R. B. H. Zmood, "Infinity control of magnetic bearings to ensure both system and external periodic disturbance robustness," in Proceedings of the 3rd International Symposium on Magnetic Suspension Technology, Washington, D.C, USA, December 1996.

[17] M. E. F. Kasarda, H. Mendoza, R. G. Kirk, and A. Wicks, "Reduction of subsynchronous vibrations in a single-disk rotor using an active magnetic damper," Mechanics Research Communications, vol. 31, no. 6, pp. 689-695, 2004.

[18] C. Elbuken, M. B. Khamesee, and M. Yavuz, "Eddy current damping for magnetic levitation: downscaling from macro- to micro-levitation," Journal of Physics D: Applied Physics, vol. 39, no. 18, pp. 3932-3938, 2006.

[19] Y. H. Guan, M. Li, T. C. Lim, and W. S. Shepard, "Comparative analysis of actuator concepts for active gear pair vibration control," Journal of Sound and Vibration, vol. 269, no. 1-2, pp. 273-294, 2004.

[20] Y. Guan, M. Li, T. C. Lim, and W. Shepard, "Comparison of actuator designs for active vibration control of a gear pair 
system," in Proceedings of the SPIE - The International Society for Optical Engineering, vol. 4693, no. 7, pp. 529-532, San Jose, CA, USA, January 2002.

[21] Y. N. Li, F. Zhang, Q. Z. Ding, and L. Wang, "The active control method and experimental study of gear meshing vibration," Journal of Vibration Engineering, vol. 27, no. 2, pp. 61-67, 2014.

[22] F. Zhang, H. Y. Li, and H. Wang, The Multi - Stage Gear Vibration Control Is Based on Adaptive Fuzzy PID Control, Journal of Huaqiao University, no. 5, Xiamen, China, 2017.

[23] Y. N. Li, F. Zhang, L. Wang, and Q. Z. Ding, "Active control of gear meshing vibration identified on line in secondary channel," Journal of Vibration and Shock, vol. 32, no. 16, pp. 7-12, 2013.

[24] G. T. Montague, A. F. Kascak, A. Palazzolo, D. Manchala, and E. Thomas, "Feed-forward control of gear mesh vibration using piezoelectric actuators," Shock and Vibration, vol. 1, no. 5, 1994.

[25] B. Rebbechi, C. Howard, and C. Hansen, "Active control of gearbox vibration," Proceedings of Active, pp. 295-304, 1999.

[26] M. H. Chen and M. J. Brennan, "Active control of gear vibration using specially configured sensors and actuators," Smart Materials and Structures, vol. 9, no. 3, pp. 342-350, 2000.

[27] Y. H. Guan, W. S. Shepard, and T. C. Lim, "Direct hybrid adaptive control of gear pair vibration," Journal of Dynamic Systems, Measurement, and Control, vol. 125, no. 4, pp. 585-594, 2003.

[28] M. F. Li, T. C. Lim, and W. S. Shepard, "Modeling active vibration control of a geared rotor system," Smart Materials and Structures, vol. 13, no. 13, p. 449, 2004.

[29] M. F. Li, T. C. Lim, and W. S. S. Jr, "Experimental active vibration control of gear mesh harmonics in a power recirculation gearbox system using a piezoelectric stack actuator," Smart Materials and Structures, vol. 14, no. 14, p. 917, 2005.

[30] X. Qiu and C. H. Hansen, "A study of time-domain FXLMS algorithms with control output constraint," Journal of the Acoustical Society of America, vol. 109, no. 6, pp. 2815-2823, 2001.

[31] M. T. Akhtar and W. Mitsuhashi, "Improving performance of FxLMS algorithm for active noise control of impulsive noise," Journal of Sound and Vibration, vol. 327, no. 3-5, pp. 647-656, 2009.

[32] I. Tabatabaei Ardekani and W. H. Abdulla, "Theoretical convergence analysis of FxLMS algorithm," Signal Processing, vol. 90, no. 12, pp. 3046-3055, 2010.

[33] I. T. A. H. Abdulla, "Theoretical Convergence Analysis of FxLMS Algorithm," Signal Processing, vol. 90, 2010.

[34] B. Huang, Y. Xiao, J. Sun, and G. Wei, "A variable step-size FXLMS algorithm for narrowband Active noise control," IEEE Transactions on Audio Speech and Language Processing, vol. 21, no. 2, pp. 301-312, 2013.

[35] X. Mu, J. Ko, and J. Rheem, "Modified FxLMS algorithm for active noise control and its real-time implementation," Journal of the Institute of Electronics and Information Engineers, vol. 50, no. 9, pp. 172-176, 2013.

[36] T. Wang and W.-S. Gan, "Stochastic analysis of FXLMS-based internal model control feedback active noise control systems," Signal Processing, vol. 101, no. AUG, pp. 121-133, 2014.

[37] M. T. Akhtar and W. Mitsuhashi, "A modified normalized FxLMS algorithm for active control of impulsive noise," in Proceedings of the European Signal Processing Conference, Aalborg, Denmark, August 2015.
[38] K. Gomathi, S. Venkatachalam, and S. Kumari, "Variable step size for improving convergence of FxLMS algorithm," Procedia Technology, vol. 25, pp. 420-426, 2016.

[39] L. Wu, X. Qiu, and Y. Guo, "A generalized leaky FxLMS algorithm for tuning the waterbed effect of feedback active noise control systems," Mechanical Systems and Signal Processing, vol. 106, pp. 13-23, 2018.

[40] J. D. Wu and J. H. Lin, "Implementation of an active vibration controller for gear-set shaft using -analysis," Journal of Sound and Vibration, vol. 281, no. 3, pp. 1037-1055, 2005.

[41] V. Balamurugan and S. Narayanan, "Active vibration control of smart shells using distributed piezoelectric sensors and actuators," Smart Materials and Structures, vol. 10, no. 2, pp. 173-180, 2001.

[42] S. Prakash, T. G. Renjith Kumar, S. Raja, D. Dwarakanathan, H. Subramani, and C. Karthikeyan, "Active vibration control of a full scale aircraft wing using a reconfigurable controller," Journal of Sound and Vibration, vol. 361, no. 3, pp. 32-49, 2016.

[43] K. Mazur, S. Wrona, and M. Pawelczyk, "Design and implementation of multichannel global active structural acoustic control for a device casing," Mechanical Systems and Signal Processing, vol. 98, pp. 877-889, 2018.

[44] Y. Pu, H. Zhou, and Z. Meng, "Multi-channel adaptive active vibration control of piezoelectric smart plate with online secondary path modelling using PZT patches," Mechanical Systems and Signal Processing, vol. 120, pp. 166-179, 2019.

[45] Y. J. Chu, S. C. Chan, C. M. Mak, and M. Wu, "A Diffusion Fxlms Algorithm For Multi-Channel Active Noise Control And Variable Spatial Smoothing," in Proceedings of the IEEE International Conference on Acoustics, Speech and Signal Processing, Toronto, ON, Canada, June 2021.

[46] T. Pepin, N. J. Pignier, and J. Rabault, "Deep reinforcement learning applied to active noise control," A Smart, Adaptive, Variable Step Size FxLMS Algorithm Design, vol. 95, 2021.

[47] G. Li, W. Liu, and X. Su, "The sun and planetary gear design of a 1.5-MW wind turbine," Journal of Vibration Engineering \& Technologies, vol. 6, 2018.

[48] L. J. Eriksson and M. C. Allie, "Use of random noise for online transducer modeling in an adaptive active attenuation system," Journal of the Acoustical Society of America, vol. 85, no. 2, pp. 797-802, 1986.

[49] R. Punchalard, "Mean square error analysis of unbiased modified plain gradient algorithm for second-order adaptive IIR notch filter," Signal Processing, vol. 92, no. 11, pp. 2815-2820, 2012. 